\title{
Estudo da Radiação na areia da praia de Meaípe
}

\author{
Calheiro, D.S. ${ }^{1 *}$; Passamai, Jr.J.L. ${ }^{1}$; Orlando, M. T. D. ${ }^{2}$ \\ 1 Departamento de Química e Física, Universidade Federal do Espírito Santo, Alegre, ES, Brasil. \\ 2 Departamento de Física, Universidade Federal do Espírito Santo, Vitória, ES, Brasil.
}

\begin{abstract}
Resumo
O objetivo deste trabalho foi fazer a medição da radioatividade na faixa de areia utilizada pelos banhistas da praia de Meaípe em Guarapari/ES, é sabido que esta areia apresenta material radioativo, pensávamos que este material ficava fixo nos pontos da praia, com a realização das medidas foi possível verificar que a areia contendo material radioativo se movimentou de um ponto para outro da praia e em alguns pontos aumentou a contagem de radioatividade e depois de algumas semanas houve diminuição da contagem no mesmo ponto.
\end{abstract}

\begin{abstract}
The objective was to make the measurement of radioactivity in the strip of sand used by Meaípe Beach bathers in Guarapari / ES, it is known that this sand has radioactive material, we thought that this material was fixed on the beach spots, to the fulfillment of measures we found that sand containing radioactive material moved from one point to another beach and at some points increased radioactivity count and after a few weeks there was a decrease of the count at the same point.

Keywords (Palavras chaves): Monazita, Radioatividade, Óxido de Tório.
\end{abstract}

\section{Introdução}

No presente trabalho foi feito medição da radioatividade da areia da praia de Meaípe. Foi observado a olho nu a faixa escura de areia (monazita) foi movimentada pela maré ao longo de toda faixa de areia utilizada pelos banhistas.

Foi possível fazer a medida a cada 15 adias aproximadamente, durante os meses de Março de 2016 até Maio de 2016, adotamos o sentido da medida de norte-sul para fazer as medidas.

\section{Apresentação dos Resultados}

Após a primeira medida realizada, foi possível constatar picos de grande intensidades localizadas a aproximadamente 450 metros do início da praia. Outro valor de $30 \mathrm{~Bq}$ foi encontrado entre 1200 metros e 1810 metros do início da praia, nesse intervalo o valor foi em toda extensão da praia.

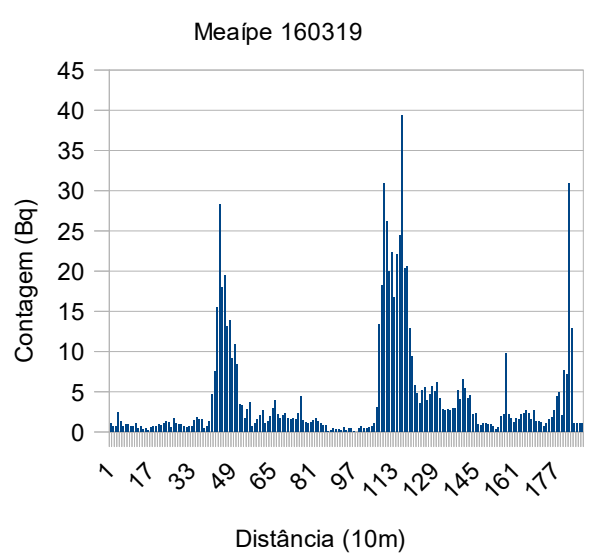


Fizemos uma segunda medida e verificamos que o pico da primeira concentração deslocou para a direita em aproximadamente 10 metros e a segunda concentração de radiação havia também se deslocado para direita em aproximadamente 100 metros e o terceiro pico diminui de intensidade.



Na próxima medida realizada foi verificada uma brusca diminuição da intensidade da radiação em toda faixa de areia em três vezes aproximadamente alcançando uma contagem de no máximo $20 \mathrm{~Bq}$.



Verificamos na medida do dia 160430 que houve um decréscimo da intensidade da radiação até a faixa de aproximadamente 1700 metros e compensação houve uma deposição mais significativa nos últimos 70 metros de faixa de areia.

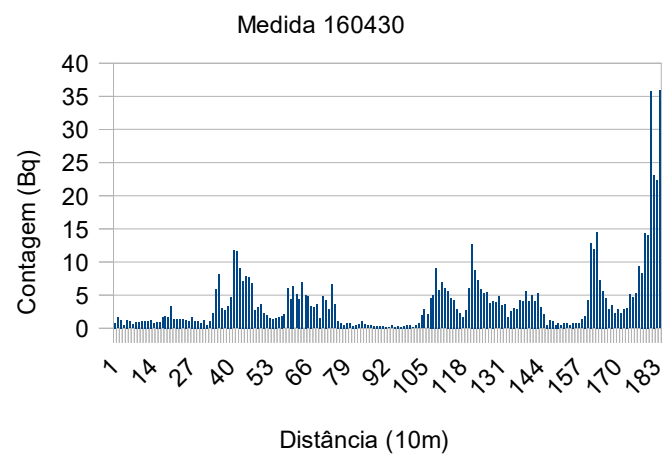

Feita nova medida verificamos um aumento de radiação entre 1600 e 1800 metros da faixa de areia utilizada pelos banhistas.



Na última medida realizada em 160526 verificamos um aumento da concentração da radioatividade entre a faixa de 1400 e 1600 metros.

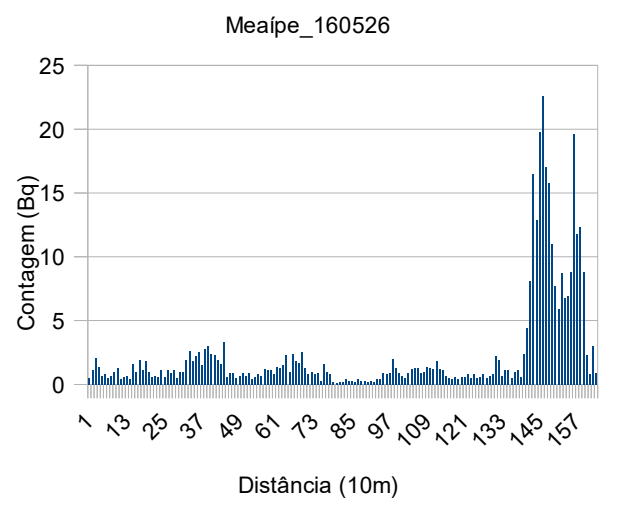

\section{Conclusões}

Em nossos estudos está sendo verificado que o material radioativo juntamente com a areia está se movimentando pela faixa de areia utilizada pelos banhistas e que a maré combinada com a ação dos ventos que atuam na praia de meaípe podem ser umas das causas responsáveis por esse movimento, os gráficos mostram que os pontos que contem material radioativo não são fixos em intensidade, devemos observar também que no mês de Março houve um aumento da intensidade da radiação chegando até próximo de $60 \mathrm{~Bq}$ que não se repetiu ainda,

\section{Referências}

FUJINAMI, N.; T. KOGA, T.; MORISHIMA. H. EXTERNAL EXPOUSURE RATES FROM TERRESTRIAL RADIANTION AT GUARAPARI AND MEAIPE IN BRAZIL. 1999.

VASCONCELOS, D.C, et al. MODELLING NATURAL RADIOACTIVITY IN SAND BEACHES OF GUARAPARI, ESPÍRITO SANTO STATE, BRAZIL. 2013. 